\title{
A RACIONALIDADE DA FÉ NO PROSLOGION DE SANTO ANSELMO
}

\author{
Paulo Martines \\ Universidade Estadual de Maringá - Paraná, Brasil
}

A razão e a fé ocupam um lugar privilegiado na obra de S. Anselmo. O conhecimento humano da realidade divina será possível mediante a conjugação desses dois termos, uma unidade na qual o exercício da razão pressupõe a presença da fé. O Proslogion é um bom exemplo para exprimir o esforço da inteligência humana para entender, ainda que parcialmente, tudo aquilo que se refere a Deus. Seu título primitivo trazia em si a idealização de um programa teológico: a fé que busca a inteligência. Muito tempo após sua redação, por sugestão do amigo Hugo - bispo de Lyon - Anselmo altera seu título para Alloquium de ratione fidei e, por fim, ao suprimir o termo ratio fidei, apresenta o nome pelo qual hoje o conhecemos: Proslogion ${ }^{1}$. Este termo de origem grega exprime a idéia de um discurso que se dirige à alma humana e a Deus. Expressões como 'razão da fé', 'razões necessárias' ou 'inteligência da fé' demarcam o sentido profundo da inteligibilidade humana do mistério divino e realçam a importância da dialética.

Indispensável para a compreensão do Proslogion é o seu prefácio, não tanto pelas informações de natureza metodológicas aí presentes, mas pelo relato de um acontecimento singular: a descoberta de um argumento que por si só seria capaz de provar que Deus é. Tal descoberta, quase uma iluminação, foi para Anselmo uma busca ansiosa, que lhe custou o sono e o apetite, bem como a falta de atenção nos exercícios espirituais da rotina

\footnotetext{
${ }^{1} \mathrm{Na}$ carta 109 (Ao arcebispo Hugo) o termo de ratione fidei aparece também no título primitivo do Monologion. Para as obras de Anselmo utilizamos as seguintes abreviaturas: P (Proslogion); M (Monologion); DLA (De libertate arbitrii); CDH (Cur Deus Homo); EIV (Epistola de Incarnatione verbi). As indicações numéricas que seguem as abreviaturas correspondem ao capítulo da obra, à página e ao número das linhas da edição crítica de F. S. Schmitt (S. Anselmi. Opera Omnia. Stuttgart: Bad Cannstatt, 1984).
}

Philosophica, 34, Lisboa, 2009, pp. 37-56 
conventual. $\mathrm{O}$ fato de o argumento ser auto-suficiente para dizer algo a respeito de Deus e de tudo o que se crê acerca da substância divina é por si só um empreendimento nada modesto da especulação medieval. Sua eficácia será colocada à prova diante da negação daquele que não aceita o credo revelado. Entendo que a argumentação dialética empreendida ao longo dos capítulos 2-4 mostrará isso. Tal empreendimento pode ser entendido sola ratione, como fora indicado claramente na obra precedente o Monologion - com a determinação exclusiva e inicial da experiência de fé. A busca guiada pela fé pode ser sola ratione, na medida em que visa explicitar a inteligibilidade intrínseca daquilo que é, de início, assunto de fé. O credo ut intelligam é a expressão mais acabada da sola ratione anselmiana.

Tomarei como pressuposto de minha leitura a afirmação de que o Proslogion é uma meditação sobre a razão da fé, realizada por aquele que deseja contemplar Deus e entender aquilo que inicialmente crê. Um esforço que se configura na conjugação da fé com a razão, na medida em que a primeira não apenas prepara o caminho a ser percorrido pela segunda, mas vem em socorro da própria razão, diante de suas limitações. Sua articulação conceitual será comandada pela presença do argumento único, que ao reconhecer que Deus é, aponta igualmente o modo pelo qual a criatura humana pode conceber algo de apropriado a respeito de Deus. A repercussão da obra foi atestada ainda na própria época de Anselmo, quando um monge de Marmoutiers, de nome Gaunilo, escreve um opúsculo em defesa do insensato (aquele que nega o ser de Deus), por entender que a argumentação de Anselmo era insuficiente para refutar a negação do insensato. Dois pontos da crítica de Gaunilo recobrem o essencial do que se disse, de Tomás de Aquino a Kant, a respeito do argumento ontológico: a) o nome dado a Deus não é um verdadeiro conceito, de modo que ele não é pensável; b) não há passagem do conceito à realidade. Em outros termos, não é possível reconhecer o 'nome' de Deus pela sua simples enunciação, sem afirmar sua existência extra-mental. A réplica de Anselmo reafirma aquilo que já foi alcançado, principalmente a necessidade para o pensamento em afirmar o ser de Deus, e instaura um fecundo diálogo filosófico acerca do papel da cogitatio humana quando voltada para algo que a transcende.

Ao reconhecer o Proslogion como uma meditação, somos levados ao sentido monástico da meditatio como um exercício de reflexão - uma adesão à experiência de fé - que nasce particularmente de uma lectio. A meditatio está na regra beneditina e os monges sabem o quanto esse exercício, que começa invariavelmente com a leitura de um texto sagrado, é igualmente uma leitura feita pelo coração ${ }^{2}$. Uma leitura que é realizada

$2 \mathrm{O}$ exercício da lectio está presente ao longo da tradição medieval, sendo parte inte- 
em silêncio, de feição puramente visual, de modo que entre ela e a meditação há a mediação do olhar: o intelecto humano vê, olha. Há certas passagens da obra de Anselmo em que os termos associados à inteligência pertencem ao ato de ver (intueri, videri) ${ }^{3}$, sempre uma atividade que busca a claritas veritatis. A visão passa a ser o mais importante dentre os sentidos, e presença constante no vocabulário de Anselmo, como por exemplo, no diálogo De libertate arbitrii, em que o funcionamento da visão (a potestas videndi) serve como modelo para explicar a vontade 4 . Não se trata da visão das coisas exteriores - visão sensorial - mas a visão interior orientada para a contemplação. A meditação está presente de modo significativo na obra de Anselmo, como fruto da espiritualidade monástica. Um dos primeiros aspectos da meditação é aquele de se inserir na conquista da interioridade, proporcionando à alma um conhecimento de si, a fim de buscar o Deus assumido pela fé. O sentido geral de meditari é pensar e refletir, logo, trata-se de um termo que corresponde a cogitare e considerare, ambos muito utilizados por Anselmo.

O século de Anselmo vê florescer, ao lado da espiritualidade monástica, as disputas públicas, nas quais temas relevantes da especulação teológica recebem o auxílio da razão. A discussão entre Berengário e Lanfranco (sobre a presença do corpo e do sangue de Cristo na Eucaristia), ou entre Pedro Damião e alguns monges do Monte Cassino (sobre a onipotência divina), ressaltam os perigos do uso excessivo da razão na busca da evidência da verdade. Nesse momento, o que está em jogo não é a oposição entre filósofos e teólogos, mas o papel da dialética, do uso da razão nos assuntos divinos. Anselmo não se envolveu diretamente com nenhuma das questões que agitavam esse século, exceção feita a sua tomada de posição diante de Roscelino. O monge de Bec afasta-se tanto de Lanfranco (no uso que faz dos recursos dialéticos disponíveis) quanto de Berengário (por não aceitar ingenuamente o poder da razão). Anselmo sabe que uma vez firme na fé, deve-se buscar as suas razões (fides stabili-

\footnotetext{
grante, no século XIII, dos instrumentos de ensino na Universidade. J. Leclercq faz com clareza a seguinte distinção: "La lectio scolastique tend vers la quaestio et la disputatio. On lui ose et on se pose, à son sujet, des problèmes: quaeri solet. La lectio monastique tend vers la meditatio et vers l'oratio. La première est orientée vers la science, le savoir; la seconde vers la sagesse, le goût. Au monastère, la lectio divina, cette activité qui commence par la grammaire, abouti, à la componction, au désir eschatologique" L'amour des lettres et le désir de Dieu. Initiation aux auteurs monastiques du Moyen Âge. 3 ed. Paris: Cerf: 1990, p. 72. Ver igualmente: R. W. Southern, Saint Anselm and his biographer. A study of monastic life and thought. Cambridge, 1966, pp. 46-47; B. Ward, "Anselme of Canterbury. A monastic scholar", In Fairacres publication 62 (1962), p. 14.

3 Cf. Carta de Recomendação do Cur Deus Homo ao Papa Urbano II. In CDH. 39-41 .

4 Anselmo, DLA. 3,213:6-25; 4, 214:3-12.
} 
tus ... in ratione eius indagine), já que o resultado desse trabalho, uma vez alcançada a inteligência da fé, serve para: a) refutar a loucura dos infiéis, da qual a infidelitas não é nada mais do que uma insipientia; b) nutrir o coração dois fiéis já purificados pela fé. $O$ trabalho de defender a fé cristã contra os ataques de seus adversários tem por finalidade rejeitar as falsidades daqueles que possuem um amor desordenado pela razão, tais como Berengário de Tours e Roscelino de Compiègne. Pertence à razão investigar certos dados da fé, que num primeiro momento parecem não possuir sentido, a fim de progredir na aquisição de certa inteligibilidade, ainda que parcial; a fé, por seu turno, prepara o caminho e dá esperanças à razão. Anselmo sabe que a razão humana não pode por si só alcançar a luz da verdade: "[...] o coração humano deve ser purificado pela fé" Proslogion nos oferecerá um caminho para pensar o sentido da busca de "razões" no domínio exclusivo da fé, do esforço da palavra humana para encontrar aquilo que já fora dito antes por uma outra palavra. Tentarei mostrar que a racionalidade da fé inscrita no Proslogion articula-se como uma meditação sobre o ser de Deus, na sua dupla constituição de oração e dialética. Meditação que prepara o espírito do homem para que este possa progredir (via inteligência) àquilo que aspira enquanto um desejo: a visio dei. Na primeira parte deste estudo apontarei a tripla constituição do Proslogion como exortação (excitatio) à contemplação, mediada pela articulação da prova (probatio) presente no exercício dialético e finalizada na alegria plena (gaudium) da visão futura. Na segunda parte, indicarei o debate sobre a possibilidade da cogitatio humana formulada na crítica de Gaunilo ao argumento e a conseqüente réplica de Anselmo. Não pretendo abordar a totalidade do Proslogion, mas destacar algumas passagens determinantes para o estabelecimento da racionalidade da fé.

\section{Excitatio}

Uma invocação em tom de oração abre o Proslogion: "E agora, pobre homem, foge um pouco de tuas ocupações, oculte um pouco teus pensamentos tumultuados. Abandona agora tuas graves preocupações e coloca à parte tuas laboriosas inquietações. Dispõe-te um pouco a Deus, e descansa um pouquinho nele. Entra na cela de tua mente, aparta-te de tudo, exceto de Deus e tudo aquilo que te ajuda a procurá-lo e, porta fechada, procure-o"6. Esta oração, longe de ser um artifício literário, aponta

5 Cf. EIV. I , 8:7.

6 "Eia nunc, homuncio, fuge paululum occupationes tuas, absconde te modicum a tumultuosis cogitationibus tuis. Abice nunc onerosas curas, et postpone laboriosas 
o caminho para a reflexão e contemplação de Deus. É um convite à introspecção, para que o homem abandone tudo aquilo que há de exterior e que, em seu interior, alcance aquilo que deseja. Desligar-se das impressões sensíveis será a condição necessária para que a alma (racional) reconheça e tenha condições de discernir aquilo que ela própria (sola et pura) deve contemplar7. A busca de Deus é, em princípio, a busca de si mesmo; aliás, um ensino presente desde o Monologion: a alma racional "quanto mais diligentemente esforçar-se em conhecer a si mesma, com tanto maior eficiência se elevará ao conhecimento da essência suprema. Quanto mais deixar de conhecer a si mesma, tanto mais se afastará do conhecimento dela"». Duas dimensões da especulação medieval encontram nesta oração inicial contornos nítidos: a) a do homem imagem e semelhança de Deus; b) a do desejo de união mística ou beatitude. Ao privilegiar o pensamento puro (abandone todas as preocupações, bem como as dúvidas a respeito das coisas), Anselmo acentua a interiorização do itinerário.

Esta oração do Proslogion apresenta uma rica forma literária - no uso que faz das rimas, das antíteses e paralelismos gramaticais - e um teor espiritual explicitado no desejo do homem elevar seu espírito para entender aquilo que crê, a fim de contemplar Deus. As referências bíblicas são abundantes ao longo do capítulo, principalmente as passagens dos Salmos e dos Evangelhos. Sua finalidade é explícita: exortar o homem a procurar Deus, de acordo com as palavras bíblicas: "procuro teu rosto, teu rosto, eu procuro"(S1 26,8). Desse pedido reconhece-se a infinita distância que opõe esse pobre homem a Deus, assinalada de forma paradoxal pela idéia da presença/ausência: "estás por toda parte e não te vejo". Como alcançar a "luz inacessível"? Os olhos do homem só vêem aquilo que não é Deus, não porque este se encontre fora do seu campo visual, mas porque ele está essencialmente fora deste campo, e por mais que sua visão se alargue, ele precisa do auxílio da fé. Num segundo momento, reconhece-se a dura condição de homem decaído, caracterizado pela "cruel queda": da beatitude na qual o homem foi feito para a infelicidade. São as marcas da dor e miséria humanas, que, diante dessa situação, o colocam tão distante de Deus. O impulso inicial da busca interior é demarcado por aquilo que atrai o espírito, por causa de sua originária semelhança, que não pode ser entendida, agora, senão na suprema dessemelhança. Ansel-

distentiones tuas. Vaca aliquantulum deo, et requiesce aliquantulum in eo, 'intra in cubiculum' mentis tuae, exclude omnia praeter deum et quae te iuvent ad quaerendum eum, et 'clauso ostio' quaere eum” (P.1, 97:4-9).

${ }^{7} \mathrm{Cf}$. EIV. prior recensio, 285:7-11.

8 "Mens rationalis quanto studiosius ad se discendum intendit, tanto efficacius ad illius cognitionem ascendit; et quanto seipsam intueri negligit, tanto ab eius speculatione descendit." (M. 66,77:21-24). 
mo explora com habilidade tópicos de natureza literária com a finalidade de reforçar a situação de miséria e aviltamento do suplicante e, ao mesmo tempo, impulsionar a alma para a contemplação do criador. Na oração o suplicante reconhece sua fragilidade e sua dependência, bem como a necessidade do auxílio divino para que, em seu socorro, ilumine seu olho (oculum mentis tuae).

Penso que esta oração deve ser entendida como a expressão de uma espiritualidade que segue as exigências de uma fé viva, resultante do amor. Esse dinamismo implica um pedido de aumento de fé; aqueles já convertidos clamam pelo aumento da conversão, 'aumenta-nos a fé' (Lc $17,5)^{9}$. Longe está a oração de ser apenas a preparação psicológica para o desenvolvimento posterior da argumentação, ou ainda um elemento de estilo. Do desejo à alegria, indicada como esperança no presente - alegria mais que plena no futuro - constrói-se as grandes linhas do Proslogion. Entre a oração do capítulo primeiro e a oração final (c.24-26), sem esquecer a oração da parte central da obra (c.14-15), encontra-se o aliquid quo nihil maius cogitare possit (algo tal que não se pode pensar nada maior), e também o quiddam maius quam cogitari possit (algo certamente maior do que pode ser pensado). A postura da oração, dirá M. Corbin, "ne représente jamais Dieu mais s'ouvre à des biens de plus en plus hauts et reconnaît que Dieu lui est de plus en plus inconnu à mesure qu'elle en devienne plus proche" 10 . No interior da lectio divina, a oração "véhicule une articulation de la parole et de la chose plus originelle que la requête ontologique"11. Após descrever essa situação e o desejo do homem, Anselmo encerra o capítulo com uma forte tonalidade agostiniana: "Não procuro, senhor, penetrar a tua profundidade, porque de maneira alguma te comparo à minha inteligência, mas desejo entender um pouco a tua verdade que o meu coração crê e ama. Com efeito, não procuro entender para crer, mas creio para entender. Pois, efetivamente creio, porque se não cresse, não entenderia" 12 .

9 Passagem bíblica citada por Anselmo no DC. III, 6, 272:24-25.

10 M. Corbin, La Pâque de Dieu. Quatre études sur S. Anselme de Cantorbéry. Paris: Cerf, 1997.

11 M. Corbin, Prière et dialectique. Introduction à l' oeuvre de S. Anselmo de Cantorbéry, Paris: Cerf, 1992, p. 317.

12 "Non tento, domine, penetrare altitudinem tuam, quia nullatenus comparo illi intellectum meum; sed desidero aliquatenus intelligere veritatem tuam, quam credit et amat cor meum. Neque enim quaero intelligere ut credam, sed credo ut intelligam. Nam et hoc credo: quia 'nisi credidero, non intelligam'" (P. 1, 100:15$-19)$. 


\section{Probatio}

O ponto de partida do procedimento argumentativo do Proslogion encontra-se na formulação de um enunciado que é precedido por uma confissão de fé: "Cremos, com efeito, que tu és algo tal que não se pode pensar nada maior"13. Deste enunciado destacam-se maius, um comparativo de superioridade (não um superlativo); a negação nihil (integrada ao verbo); o verbo cogitare, em referência à capacidade de pensar, de modo a expressar uma interdição (ou proibição) dirigida ao pensamento, que no caso específico, sabemos se tratar da impossibilidade de se pensar algo maior que Deus. Este enunciado é o argumentum apontado no prefácio Proslogion, capaz de provar, sem a menor dúvida (procul dubio) aquilo que pode ser dito a respeito de Deus. Ele possui em si, dirá ainda Anselmo, uma força de significação (vis significativa) que reconhece a necessidade daquilo que é inteligido ou pensado ${ }^{14}$. A eficácia do argumentum será explicitada ao longo da argumentatio propriamente dita. Ambos os termos pertencem ao vocabulário da dialética, em grande parte transmitida, no século de Anselmo, pelos comentários e obras pessoais de Boécio. Dialética aqui, nada mais é do que um método de discussão ou uma técnica para descobrir argumentos.

Um argumento na língua de Boécio serve para resolver uma questão, que inicialmente apresenta uma dúvida, ou é fruto de uma dificuldade: "argumento é uma razão que produz crença a respeito de algo que era duvidoso"15. Mas o argumento, ainda segundo Boécio, é diferente da argumentação: "chama-se argumentum o sentido (vis sententiae) e a razão ( $r a-$ tio) que se estabelece nos limites de um discurso (oratio), quando algo, que era incerto, é provado; mas a expressão (elocutio) do argumento é chamada argumentação. Então, o argumento é a força (virtus), conteúdo mental (mens) e sentido da argumentação; esta, por sua vez, é a explicitação do argumento mediante a significação do discurso (oratio)"16. A prova indireta, ou reductio ad absurdum, será o mecanismo presente no desenvolvimento da argumentação ao longo do capítulo 2 do Proslogion.

A partir da negação do insipiens, instaura-se o longo movimento argumentativo do qual resultará o reconhecimento de que Deus não apenas

13 "aliquid quo nihil maius cogitari possit" (P. 2,101:5). Uma variante desse enunciado aparece sob a forma "id quo maius nequit cogitari" (P. 3,102:8-9). Uso, a partir daqui, a forma abreviada Id quo maius para me referir ao argumentum.

14 Anselmo, Resposta de Anselmo a Gaunilo, 9 138, 28-31.

15 Boécio, In Ciceronis topica 2.7 - 2.8. Translated, with notes and an introduction by Eleonore Stump. London: Cornell University Press, 1978.

16 Boécio, De topicis differentiis, I 1174d 23-30. Translated, with notes and an introduction by Eleonore Stump. London: Cornell University Press, 2004. 
é (cap. 2), mas que não pode ser pensado não-ser (cap. 3), pois é algo maior (quiddam maius) do que pode ser pensado (cap. 15). Vejamos com atenção cada um desses passos.

A negação do insipiens aparece na estrutura argumentativa do Proslogion como um reativo ao pensamento dialético: "Ou será que não há tal natureza, porque 'disse o néscio no seu coração: não há Deus""17. O insipiens não é uma figura retórica, mas aquele que, dotado de certa racionalidade, é capaz de refutar o dado revelado. Com sua negação, o nome de Deus é isolado, tanto da invocação, quanto de sua existência e, fato importante, tal negação instaura ao longo dos capítulos 2-4 uma discussão de caráter filosófico, estabelecida na condenação da cogitatio vocum. Sua negação é uma vox que não alcança significação alguma. A argumentatio reunirá aquilo que já estava confirmado pela fé e o que foi dissociado pelo insipiens. Aquilo que já estava afirmado pela fé e que, do ponto de vista do homem de fé, não precisa mais ser provado, agora ganha um espaço novo e maior. Anselmo procura mostrar que a afirmação do insipiens é vazia e sem conteúdo, contraditória em si, uma estultice que exige superação.Anselmo parte de algo que o insipiens não pode negar, isto é, do fato de que ele tem um certo entendimento do id quo maius. Quando o insensato ouve a expressão "algo tal que não se pode pensar nada maior", entende o que ouve, isto é, tal expressão possui um sentido para ele. $\mathrm{O}$ que entende está presente na sua inteligência, ainda que não pense o que este algo é; em outras palavras, ele não reconhece a força ontológica de tal designação. O que está em jogo aqui é um pressuposto universal, que faz do insipiens um auditor intelligens.

O que aparece aqui é a existência de um mínimo essencial que permite ao insipiens pelo menos formular sua negação, que não pode ser feita sem pensar ao mesmo tempo no nome de Deus. A lei de contradição serve de medida fundamental para a dialética: não é possível negar sem entender o que está sendo negado. O que se espera do contendor é que ele diga algo, e ainda que tal conteúdo não seja aceito pelo interlocutor, a sua fala permite guardar a condição básica do discurso, do pensamento coerente. Anselmo ao longo da argumentatio visa formular não uma demonstração, mas uma refutação; em outros termos, não se trata de demonstrar que há um conteúdo real da proposição 'Deus é', mas apontar que a proposição oposta é contraditória.

Anselmo distingue, nos passos iniciais da argumentação, o fato de algo estar na inteligência e o fato de entender o que este algo é. Não se passa imediatamente do ideal para o real: imaginar uma ilha perfeita não a faz existir. $\mathrm{O}$ exemplo de Anselmo é sugestivo: a relação entre a preco-

17."An ergo non est aliqua talis natura, quia 'dixit insipiens in corde suo non est deus?' "(P. 2,101:5-7) Salmos 13,1 e 52. 
gitação do pintor e a obra realizada. O pintor tem na inteligência (in intellectu) aquilo que pretende realizar, mas não entende o que é, aquilo que ainda não fez. Quando realizar aquilo que pretende, além de possuí-lo na inteligência, entenderá que é, o que já fez ${ }^{18}$.

Não me parece que se trata de uma afirmação sobre a existência ou não do quadro, mas de uma afirmação que se situa no nível do conhecimento que o pintor tem ou não do quadro, ou, melhor dizendo, de certo tipo do conhecimento: in intellectu solo (na inteligência somente), ou o entendimento do que a coisa é. Anselmo está convencido de que o id quo maius está na inteligência, pois aquilo que o insensato ouve e entende está na inteligência.

Estamos aqui, certamente, no coração do argumento, no ponto em que a argumentação alcança um rigor formal explicitado pelo princípio de não-contradição, segundo o qual uma coisa não pode 'ser' e 'não ser' ao mesmo tempo (impossibili est simul esse et non esse). A formulação de Anselmo é simples: ora, o id quo maius não pode estar somente na inteligência; se tal ocorresse, poder-se-ia também pensar na coisa (in re), o que é maior (quod maius est). Neste caso, conclui-se: o id quo maius não seria o id quo maius, o que certamente é impossível, porque é contraditório. Portanto, o id quo maius existe et in intellectu et in re. Em outros termos, o que Anselmo mostra é que algo que existe na mente e fora dela é maior do que existir apenas na mente. A posição in intellectu conduz, pelo raciocínio instaurado pelo nome, à outra posição do ser: in re. A argumentação pressupõe, desse modo, o reconhecimento de uma ordem na qual há uma disposição gradual dos seres, segundo a sua forma de inteligibilidade. Anselmo não tenta demonstrar que o existir representa uma perfeição, de modo que um conceito pensado com a existência seja maior do que o mesmo conceito pensado sem a existência.

A prova termina ao fim do capítulo 2 , com a afirmação da existência do aliquid quo nihil maius cogitari possit, na inteligência e na realidade, não como se a tivesse deduzido de sua essência ou de uma representação inteligível, mas de um movimento da inteligência que reconhece aquilo que está nela e aquilo que a transcende, que de início é real. Não apenas é reconhecido que Deus é tal como cremos, mas que ele é de tal modo que não pode ser pensado não-ser, afirmação que reenvia à noção de um ente necessário, distinto dos entes contingentes: "Portanto, tu és assim verdadeiramente, senhor meu Deus, que não pode ser pensado não ser"19. Apenas o ser divino é verdadeiro, de modo que tudo aquilo que é diferente dele, tem menos ser (minus habet esse).

18 Cf. P. 2,10:10-13.

19 "Sic ergo vere est, domine deus meus, ut nec cogitari possit non esse" (P. 3, 102:6). 
O movimento dialético presente na argumentação de Anselmo, ao explicitar a forma negativa do nihil maius, delineia um campo semântico muito mais amplo que uma afirmação positiva. Como bem notou M. Corbin, o procedimento dialético de Anselmo é aquele de utilizar a razão para resolver, em favor da fé, os debates suscitados pelos infiéis: "La proposition qu'il faut tenir pour vraie est celle qui dispose d'un argument plus solide que l'autre, d'une raison qui fait pencher la balance en sa faveur et qui, en ce sens, comme nous le disons couramment, lui donne raison et fait foi. L'argument engendre un assentiment (fides) à propos d'une chose qui, au départ, était objet d'hésitation (res dubiae)"20.

Se a argumentação empreendida até aqui reforça a idéia da impossibilidade de se pensar algo maior que Deus, indicada pelo nihil maius, isso não condiciona negativamente o trabalho da razão, não a impede de reconhecer uma significação positiva e ontológica, na qual Deus é summum omnium, o único existente por si (solum existens per seipsum) e que criou todas as coisas do nada. Anselmo remove qualquer inconsistência ou dificuldade que parece existir na possibilidade de a linguagem humana atribuir certas "propriedades" a Deus: "tu és justo, verdadeiro, feliz e tudo aquilo que é melhor ser do que não ser. De fato é melhor ser justo do que não ser justo, feliz do que não ser feliz" ${ }^{21}$.

Ainda que o id quo maius não pudesse ser pensado ou entendido, não seria falso ser pensado ou entendido, do mesmo modo que podemos dizer "inefável", ainda que este signifique indizível, ou pensar "impensável", ainda que deste nada possa ser pensado ${ }^{22}$. $\mathrm{O}$ insensato não pode dizer que não pode pensar/entender o que é dito, sob pena de ser considerado um impudente (impudens), ou, o que seria pior, caso persistisse na negação, poderia ser tachado como digno de desprezo (conspuendus).

A explicação da negação do insensato recai sobre os diferentes modos pelos quais se pode pensar algo: segundo a palavra que a significa, ou segundo a própria coisa que é. O insipiens age como um dialético in voce, que pretende reduzir tudo a meras palavras, sem atentar para aquilo a que as palavras se referem: a res. O Proslogion 4 explora exatamente o quomodo da insipientia, a partir da identidade entre 'pensar' e 'dizer no coração": "como [o néscio] disse no coração o que não pôde pensar"23. O

20 M. Corbin, Anselme. Paris: Cerf, 2004, p. 68.

21 "Tu es itaque iustus, verax, beatus, et quidquid melius est esse quam non esse. Melius namque est esse iustum quam non iustum, beatum quam non beatum" (P.104,5:15-17). O recurso à noção de melius aprofunda a compreensão do summum, na medida em que este não será considerado como o ser que coroa a série de relativos, mas sim, nele mesmo, do ponto de vista da sua excelência qualitativa.

22 Anselmo, Resposta a Gaunilo, 9,138:11-15.

23 "quomodo dixit in corde quod cogitare non potuit" (P.4,103:14-15). 
pensamento nasce de um verbo interior (dito no coração), que posteriormente é exteriorizado em palavras articuladas. A cogitatio se dá em primeiro lugar no espírito que se esforça por exprimir uma semelhança da coisa no seu pensamento, através da imagem guardada na memória. $\mathrm{O}$ pensar será mais verdadeiro (veraciter cogitare) quanto mais exprimir a própria coisa (res). O De grammatico, ao elaborar uma teoria da significação, apontará para uma significatio per aliud, distinta de uma significatio per se. Esta última, distante da significação mundana, relaciona-se com aquilo que é apreendido em sua essência por pura intelecção. Há um nível elementar de significação marcado pela correspondência entre os sons proferidos e a coisa ela própria: "mas já que os sons proferidos não significam senão as coisas, ao dizer o que é aquilo que os sons proferidos significam, diz-se necessariamente o que são as coisas" ${ }^{24}$. Essa forma de significação pertence propriamente ao domínio dos signos sensíveis (signis sensibilibus) - primeiro termo da divisão tripartida apresentada no Monologion ${ }^{25}$-, que nas palavras de Anselmo é o uso sensível daquilo que os sentidos corporais podem receber; por exemplo, utilizando a palavra homem para significá-lo. Duas outras formas são igualmente indicadas: a) de forma insensível, isto é, pensando insensivelmente (insensibiliter cogitando) no interior de nós mesmos esses mesmos signos, por exemplo, quando penso nesse homem; e b) nem sensivelmente, nem insensivelmente, mas pela imaginação corporal (imaginatione corporum) ou pelo intelecto racional (rationis intellectu); quanto ao primeiro, imagina-se homem pela sua figura sensível, e, quanto ao segundo, pela razão quando se pensa a essência universal, a saber, animal racional mortal. Essa palavra não é expressa por signos convencionais das diferentes línguas, mas é palavra no seu sentido universal, que todos os homens entendem $^{26}$.

Mas resta ainda um passo a ser dado. Da formulação e articulação do argumento único, foi possível estabelecer que o pensamento pode se referir a Deus de modo conveniente, como "algo tal que não se pode pensar nada maior" (cap. 2), afirmando que pensá-lo retamente implica a necessidade desse pensamento (cap. 3) e que a negação do insensato é explicada por um certo modo de pensar (cap. 4). Ao fim desse processo, alcançou-se o que era procurado? A interrogação é formulada por Anselmo e dirige-se para a alma que, desde o início, é motivada pela procura e anseia o encontro com Deus: "Oh! minha alma, encontraste o que procura-

24 "Sed quoniam voces non significant nisi res: dicendo quid sit quod voces significant, necesse fuit dicere quid sint res" (DG. 17,162:25-26).

25 Cf. M. 10, 24:30-31.

26 Cf. M. 10, 25:1-9. 
vas?"27. Ao que foi supostamente encontrado, resta o sentimento da decepção, de não tê-lo encontrado. Como pensar uma grande ausência, numa presença tão íntima? O pedido clama pelo entendimento, para que se alcance a visão. O Deus oculto para a alma suplicante é transcendente e fonte de toda a verdade: "Quão grande é aquela luz donde desponta todo o verdadeiro que ilumina o espírito racional. Quão profunda é aquela verdade na qual se encontra tudo o que é verdadeiro"28.

Todo esforço intelectual humano será aquele de progredir na inteligência, para alcançar a visão. Anselmo deixa entrever algo como uma tensão entre o desejo de ver e a sua realização: a alma humana, no esforço de ver puramente aquilo que deseja, "vê que não pode ver mais"29. A inteligência humana reconhece, ao fim de sua busca, mais do que ela poderia alcançar. A fé busca a inteligência, e esta pede que se creia mais, diante do incompreensível. O aspecto negativo, demarcado por esta distância infinita entre o homem e Deus, e a impossibilidade de alcançá-lo, não é uma carência, mas uma riqueza inexaurível, que conduz o pensamento a reconhecê-lo como "algo maior do que pode ser pensado"30. A inteligência da fé alcançada pela razão é tão somente o entendimento humano da incompreensibilidade divina, conforme o ensinamento do Monologion: "Parece-me que o mistério desta coisa tão sublime transcenda o alcance da inteligência humana" (...) "para quem investiga uma coisa incompreensível, é suficiente alcançar, mediante a razão, o conhecimento certíssimo dela, ainda que não consiga penetrar com a inteligência como ela é deste modo" 31 . Vale lembrar, nesse sentido, o ensinamento presente na obra cristológica de Anselmo, o Cur deus homo: por mais que se possa explicar os motivos da encarnação, pelos quais Deus restaurou a criatura humana, sempre haverá algo que não pode ser expresso pela capacidade humana de conceber, sempre haverá rationes altiores (Cur deus homo, I,2). O ato misericordioso de Deus é considerado "tão grande e tão concordante com a justiça, que não pode ser pensado nem maior ou mais justo" 32 .

27 “An invenisti, anima mea, quod quaerebas?" (P. 14,111:8).

28 "Quanta namque est lux illa, de qua micat omne verum quod rationali menti lucet. Quam ampla est illa veritas, in qua est omne quod verum est" (P. 14, 112:4-7).

29 "videt se non plus posse videre" (P.14,111:25;112:1).

30 "quiddam maius quam cogitari possit" (P. 15,112:14-15).

31 "Videtur mihi huius tam sublimis rei secretum transcendere omnem intellectus aciem humani" (...) "Sufficere namque debere existimo rem incomprehensibilem indaganti, si ad hoc ratiocinando pervenerit ut eam certissime esse cognoscat, etiamsi penetrare nequeat intellectu quomodo ita sit" (M. 64,74:30-31; 75:1-3).

32 “(...) tam magnam tamque concordem iustitiae invenimus, ut nec maior nec iustior cogitari possit” (CDH.II,20,131:27-29). 


\section{Gaudium}

A beatitude esperada pelo homem será a presença da alegria plena. Esse é o tema proposto pelos capítulos 24-26, que encerram o Proslogion. A perspectiva dessa beatitude será o coroamento do esforço daquele ardente desejo da união com Deus, indicado no início da obra. De fato, é como se o fim indicasse e condicionasse o início; e o início é início de seu fim. É o momento em que Anselmo considerará os bens do corpo e da alma presentes nesta vida e sua respectiva referência com a promessa futura.

O estilo meditativo desse grupo de capítulos reencontra o esforço do intelecto humano na busca de entendimento. O movimento argumentativo desenvolvido por Anselmo está estruturado na série de conjecturas (coniectationes) que faz acerca desse bem, entendido como supremo e por si: "Agora minha alma, desperta e eleva toda tua inteligência, pensa o quanto podes, qual é e quão grande é esse bem" 33 . As conjecturas procuram elevar o pensamento para algo que está além, para algo que não apenas é maior, no sentido do maius enfatizado no argumento único, mas é quiddam maius. Se determinado bem singular é agradável, por exemplo, como não será aquele que encerra todos os bens? Se a vida criada é boa, a qual ponto chegará a vida criadora? Essa é a estrutura do raciocínio de Anselmo: o quale e o quantum, talvez de origem aristotélica via Boécio, mais a categoria de relação, demarcam a forma do pensamento. Interessante ressaltar que os verbos estão no tempo futuro, reafirmando a dimensão escatológica dessa meditação.

No entanto, é na consideração dos bens do corpo e da alma - objetivo do cap. 25 - que a reflexão sobre o homem e o seu futuro surge de maneira clara, assumindo uma dimensão ética. Que esse homem miserável - um homem de nada (homuncio), segundo os termos do cap. 1 - não busque aqui os bens do corpo e da alma, mas lá em Deus. O que se espera está muito além do homem: "o olho nunca viu, o ouvido nunca ouviu, nem o coração nunca imaginou" - versículo de S. Paulo (I Cor 2,9), citado textualmente por Anselmo e central para a leitura do capítulo. Os bens do corpo (de ordem material) são em número de sete: beleza, força, longevidade, saciedade, ebriedade, melodia e voluptuosidade. A abordagem de cada um desses bens repete uma estrutura já apresentada segundo a categoria de relação: aqueles que amam a beleza (corporal) devem saber que há algo mais belo como o Sol (através da citação de Mt 13,43: "os justos resplandecerão como o Sol"). Do mesmo modo para aquilo que

33 "Excita nunc, anima mea, et erige totum intellectum tuum, et cogita quantum potes, quale et quantum sit illud bonum" (P. 24,117:25-6). 
Anselmo entende como melodia: não há nada como o coro dos anjos cantando a Deus.

Os bens da alma - os primeiros de ordem intelectual - encontram também a sua plenitude em Deus e, como na divisão acima, aparecem em número de sete: sabedoria, amizade, concórdia, poder, honras, segurança e alegria. A sabedoria não será aquela que o homem pode alcançar por suas próprias forças, porém será a sabedoria de Deus revelada ao homem. $\mathrm{Na}$ consideração da concórdia e poder, aparece, como eixo central, a vontade. Na verdadeira concórdia, todos terão uma só vontade, que não será outra senão a vontade de Deus. Trata-se de uma fórmula que relembra os termos do diálogo Sobre a liberdade de arbitrio, no qual a vontade reta se identifica com o querer de Deus ${ }^{34}$. Essa proximidade, quase identidade entre as vontades, se manifesta igualmente na expressão da potestas, outro bem da alma, na qual vamos encontrar a sinonímia voluntas-velle. Diz Anselmo: "Se desejam o poder, terão uma vontade onipotente como a de Deus, e assim como Deus pode o que quer por si mesmo, eles poderão o que quiserem, por meio dele" 35 . Todo esse movimento não explicita outra coisa senão a alegria plena, plenitude acordada ao coração, mas igualmente plenitude de alma e mente. Essa alegria plena será aquela da qual gozarão os eleitos. Ao homem cabe tentar conhecer e sempre amar Deus - são essas as súplicas da parte final da oração - pois, ainda que não seja possível tê-lo integralmente nesta vida, que o homem ao menos progrida dia a dia até que alcance a plenitude.

\section{II}

\section{Gaunilo e a defesa do insensato}

O trabalho crítico de Gaunilo pode ser reduzido à seguinte idéia: o argumentum apresentado por Anselmo é insuficiente para refutar a negação do insipiens, de modo que este pode negar a existência de Deus ${ }^{36}$. A

34 A vontade reta do homem se identifica com o querer divino, na medida em que deve querer aquilo que Deus quer. Pode-se muito justamente falar aqui de uma submissão à vontade de Deus, que não é uma servidão (DLA. 8, 220:17-19).

35 "Si potestas: omnipotentes erunt suae voluntatis ut deus suae" (P. 25, 119: 8-9).

36 As objeções de Gaunilo são apresentadas em seu opúsculo Quid ad haec respondeat quidam pro insipiente (doravante Defesa do insensato $=\mathbf{D I}$ ), escrito muito provavelmente logo após a redação do Proslogion. A réplica de Anselmo intitula-se Quid ad haec respondeat editor ipsius libelli (doravante Resposta de Anselmo = RA). Por decisão do próprio Anselmo, esses dois textos fazem parte, desde o primeiro momento, do Proslogion. Cf. Eadmer, Vita Anselmi, I,19. De Gaunilo, sabe-se apenas que foi monge em Marmoutiers (perto de Tours) e que morreu em 1083. Cf. R. W. Southern, Saint Anselme and his biographer. A study of monastic life and thought. Cambridge: Cambridge University Press, 1966, p. 65. 
fazer a defesa do insipiens, o monge de Marmoutiers coloca-se como um verdadeiro interlocutor, que, ao assumir determinada posição filosófica, permite o diálogo sobre o papel da cogitatio humana. Gaunilo não faz a defesa do ateísmo, pois, como monge, sabe que Deus é tal como a fé ensina. Ele é um catholicus pro insipiente, jamais um insipiens; Anselmo, por sua vez, não quer convencer o insensato, nem realizar a demonstração da existência de Deus, mas como tentei mostrar acima, elabora uma meditação acerca da força e limites do pensamento humano. $O$ terreno no qual essa "disputa" se dará é o mesmo: aquele demarcado pela fé. Anselmo fará apelo à fé e à consciência de Gaunilo, tal como a um argumento consistente para rebater aquilo que julga não passar de falsidades. Uma discussão que aprofunda a busca pela racionalidade da fé.

O opúsculo de Gaunilo contém oito parágrafos. O primeiro apresenta resumidamente o argumentum de Anselmo, assim entendido por Gaunilo: a) aquilo que o insensato ouve (que há uma natureza da qual não se pode pensar nada maior) tem um significado em si mesmo; b) essa natureza não existe apenas na inteligência, mas também na coisa. Tal exposição sumária consubstancia, por assim dizer, os dois pontos fundamentais de sua crítica, a saber: que o nome dado a Deus não é um verdadeiro conceito, de modo que não é pensável (§ 2-4) e de que não há passagem do conceito à realidade (§5-8). Gaunilo, ao longo de sua argumentação, usa a expressão maius omnibus, no lugar de id quo maius, de modo a acentuar a presença de um ente máximo, entre os entes possíveis.

A primeira objeção de Gaunilo $(\S 2)$ diz respeito à presença de um determinado conteúdo (no caso o id quo maius) na inteligência, pelo simples fato de tê-lo ouvido. Tal fato é contestado, visto que se poderia ter a inteligência a respeito das coisas falsas e inexistentes ${ }^{37}$. Em outras palavras, a principal crítica de Gaunilo recai sobre a passagem das voces à conceptio. Como a compreensão daquilo que é ouvido pode permitir a fundação do conceito?

Com relação ao id quo maius, afirma Gaunilo, não se pode pensá-lo a não ser pelo entendimento, isto é, "compreendendo por ciência que algo existe na coisa" (scientia comprehendendo re ipsa illud existere) ${ }^{38}$. O intelligere tem um domínio exclusivo, que é aquele de voltar-se para a res.

Em linhas gerais, um pensamento (cogitatio) só pode ser verdadeiro, quando indica a coisa da qual ele trata: "Com efeito, nem conheço a própria coisa (que é Deus) nem a posso conjecturar a partir de uma coisa semelhante" 39 . O exemplo a seguir indica muito bem quais são os pressu-

37 Cf. DI. 2,125:14-21.

38 Cf. DI. 2, 125:21; 126:1.

39 "Neque enim aut rem ipsam novi aut ex alia possum conicere simili" (DI. 4,127:4) 
postos de Gaunilo: ao ouvir alguma coisa sobre um homem completamente desconhecido, poder-se-ia ao menos pensar segundo a própria coisa que é o homem, "graças a este conhecimento específico ou geral que possibilita conhecer o que é o homem ou o que são os homens" 40 . No caso específico do id quo maius, é impossível pensar Deus antes de saber que Deus existe. Ora, não o sabendo, posso pensá-lo como não ser (hoc ipsum etiam non esse cogitare possum). Pensar segundo a significação da palavra ouvida, e sendo a mesma desconhecida, faz com que se produza certo movimento da alma que se esforça para reproduzir a significação da palavra percebida. Esse conatus da alma não chega a atingir um conhecimento verdadeiro.

O que temos aqui é uma teoria da significação, ou pelo menos a sua indicação, cuja validade se constitui pela indicação e referência daquilo que é de domínio real, manifestado pela experiência direta. Numa linguagem que não é aquela de nossos interlocutores, poder-se-ia dizer que o real, para Gaunilo, é confirmado pela experiência e, para Anselmo, o real é concebido pela inteligência, nada mais do que uma atividade puramente conceitual.

Uma segunda objeção de Gaunilo (§ 5) diz respeito à passagem do intelligere ao domínio da res. Essa passagem é preciso ser provada por um argumento indubitável (argumentum indubius) ${ }^{41}$. Como afirmar que existe esse algo, que é completamente ignorado e pelo qual a alma se esforça para reproduzir segundo a palavra ouvida? É necessário, diz ainda, que o id quo maius esteja em alguma parte na coisa verdadeira, de modo que subsista por si mesmo. Passar de um conteúdo puramente pensável para a sua existência real é como afirmar a veracidade da parábola da ilha perdida: ela existiria necessariamente pelo fato de se ter formulado uma série de maravilhas a seu respeito. Quem afirma isso, diz Gaunilo, não faz mais do que pilhérias; será um estulto, não apenas aquele que acreditar nisso, mas aquele que tentar provar com alguma certeza a existência dessa ilha.

Uma terceira objeção de Gaunilo refere-se à utilização do verbo cogitare, na formulação do argumento de Anselmo: "quando se diz que esta coisa suprema não pode ser pensada não ser, talvez, seria melhor dizer que não pode ser entendida não ser"42. Referindo-se ao sentido do verbo intelligere, Gaunilo observa que não é possível entender as coisas falsas,

40 "per illam specialem generalemve notitiam qua quid homo vel homines novi" (DI. 4, 127:5-6).

41 Cf. DI. 5,128:2.

42 "Cum autem dicitur quod summa res ista non esse nequeat cogitari: melius fortasse diceretur quod non esse aut etiam posse non esse non possit intelligi"(DI. 7,129:10-12). 
mas elas podem ao menos ser pensadas. Parece que o verbo cogitare recebe uma acepção mais abrangente segundo Gaunilo, como na consideração da sua própria existência: "sei indubitavelmente que sou, mas posso não ser. Porém, pensar que não sou, enquanto sei de modo certo que sou, não sei se posso" 43 .

\section{Resposta de Anselmo}

Anselmo não hesita, desde o primeiro momento de sua resposta, em acentuar o pensamento do homem, ao exprimir o esse de Deus: se é possível pensá-lo, é necessário que ele seja (si vel cogitari potest esse, necesse est illud esse $)^{44}$. Tudo o que é diferente do ser supremo, isto é, que possui começo ou fim, pode ser pensado como não ser. Quando o insipiens ouve a expressão id quo maius nequit cogitari, ele a tem na inteligência. Essa proposição, necessária para a intelecção daquilo para o qual a mente se dirige, é confirmada nas respostas às objeções ${ }^{45}$, a partir da seguinte relação: do mesmo modo que o que é pensado está no pensamento, também aquilo que é entendido está na inteligência. Anselmo aponta a contradição de Gaunilo no que diz respeito à proposição das coisas falsas e inexistentes, que poderiam ser entendidas: ora, se assim fosse, como é possível afirmar que entender é compreender por ciência que algo existe na coisa? $\mathrm{O}$ id quo maius é entendido e está na inteligência, antes mesmo de existir na própria coisa ${ }^{46}$.

A argumentação do Proslogion não procura apresentar uma demonstração acerca da existência de Deus, como se fosse uma passagem do conceito presente na mente à existência. A parábola da ilha perdida não se aplica ao caso em questão proposto pelo argumento de Anselmo, visto não se tratar de uma grandeza. Cabe ressaltar que Gaunilo entende a fórmula anselmiana como maius omnibus. O id quo maius, para Anselmo, "existe segundo uma certa razão da verdade", não podendo ser pensado como não ser. Essa lição já havia sido entrevista no Monologion, que, ao considerar a natureza divina segundo as noções de simplicidade, unidade e transcendência, afirmava: "somente ela parece ser, ao passo que as outras coisas, quando comparadas a ela, não são" ${ }^{47}$. Anselmo, de modo irô-

43 "Et me quoque esse certissime scio, sed et posse non esse nihilominus scio. (...). Cogitare autem me non esse quandiu esse certissime scio, nescio utrum possim" (DI. 7,129:14-18).

44 Cf. RA. 1,131:2-3.

45 Cf. RA. 2,132:14-30.

46 Cf. RA. 6, 136:10-15.

47 Cf. M. 28., 45:25-26. 
nico, sustenta que, caso alguém insistisse na existência de tal ilha, não mediria esforços para encontrá-la e devolvê-la ao seu dono, para que não ficasse mais perdida ${ }^{48}$.

Os parágrafos 4 e 8 da Resposta de Anselmo apontam respectivamente para a elucidação do vocabulário utilizado no argumento e para uma nova consideração do conhecimento de Deus. Vejamos aquilo que diz respeito ao vocabulário.

Na designação "algo tal que não se pode pensar nada maior", deve-se preferir o uso do verbo cogitare a intelligere. Para todas as coisas que têm começo, fim ou são divididas em partes, podemos pensar que não são, enquanto sabemos que são, exceto o ser supremo ${ }^{49}$. Ora, pensar que as coisas não são, enquanto são, é reduzir-se a um pensamento imaginativo, ao domínio da ficção: apenas afirmamos isso "não as considerando atentamente, mas fingindo-as ser o que pensamos" 50 . No caso do id quo maius, o cogitare deve se conformar à intelecção determinada pela própria inteligência.

Quanto à possibilidade de se duvidar da própria existência, ou de pensar a não existência, Anselmo declara: "pode-se pensar que não és, enquanto sabes de certo modo que és", porque é efetiva a nossa capacidade de pensar a primeira coisa, bem como o nosso conhecimento da segunda. $\mathrm{O}$ que não é possível é ter a cogitatio da não existência sob a mesma forma, isto é, ao mesmo tempo no qual sabemos existir.

O parágrafo 8 da resposta às objeções alarga o campo de compreensão do id quo maius. Se o insipiens pode duvidar da presença do id quo maius na mente, pelo fato de se tratar de uma palavra ouvida, sem qualquer referência à própria coisa, ele não pode contestar algo que é universal e acessível a todos: o reconhecimento de que os inumeráveis bens remontam a um bem primeiro e supremo. Ainda que haja diferenças e mesmo desigualdades na natureza das coisas, nada nos impede de reconhecer algo que não está submetido a essa estrutura hierárquica: "como não se pode negar que certas naturezas sejam melhores que outras, a razão nos persuade ao menos que certa, dentre elas, seja supereminente, de tal sorte que não tenha superior"51. Desse modo, há uma única natureza

48 Cf. RA. 3, 133:8-9.

49 Anselmo ao considerar no Proslogion (cap. 19-21) a relação entre as coisas do mundo - sujeitas às marcas do passado-presente-futuro - e Deus, que está fora do tempo e não possui partes, afirma que a eternidade de Deus não poderá ser pensada como algo que foi, é ou será, mas como algo que simplesmente é (simpliciter es), fora de todo tempo (extra omne tempus).

50 "Non existimando, sed fingendo ita esse ut cogitamus" (RA. 4,134:9-10).

51 "Cum igitur naturarum aliae aliis negari non possint meliores, nihilominus persuadet ratio aliquam in eis sic supereminere, ut non habeat se superiorem" (M. 4,17:3-5). 
superior a tudo o que existe, de maneira que não admite ser inferior a nenhuma outra: ela é por si aquilo que é, todas as demais coisas são por ela o que elas são. Vale observar que Anselmo, ao enfatizar essa idéia de uma hierarquia entre as naturezas, não pensa numa natureza que coroasse a série de seres finitos, como se ela fosse a maior dentre todas. O ser supremo (per se) é apresentado de uma forma negativa, na medida em que ele não pertence à série, a qual funda, ele não é inferior a nada. Se o $a r$ gumentum do Proslogion não é suficiente para levar ao reconhecimento do ser supremo, Anselmo relembra ao catholicus Gaunilo que Deus pode ser conhecido (pela luz natural da razão), a partir das coisas criadas. Em seu apoio, é citado literalmente o versículo de S. Paulo - Rom 1, $20^{52}$.

A resposta de Anselmo às objeções apresenta-se como uma confirmação da argumentação dialética empreendida no Proslogion. A intelecção do id quo maius nequit cogitari não é formulada segundo uma metodologia dedutiva aristotélica, mas como a clarificação de certo conteúdo significativo, uma explicação da verdade contida num pensamento e expressa na fala. Busca-se, em outras palavras, a articulação do discurso significante e do raciocínio.

Razão e fé coincidem mutuamente no esforço da inteligibilidade da realidade de Deus. A confissão de fé não elimina o trabalho da argumentação dialética, antes, prepara o seu caminho, pois a razão sabe que para entender é preciso crer, e o próprio entendimento alcançado exige ainda mais fé, ao reconhecer a incompreensibilidade divina. A confissão de fé aponta o desejo da busca pelo homem da beatitude eterna e também a sua limitação (e fraqueza): "em ti sou, e não posso chegar até ti”. Os olhos humanos nas trevas não implicam carência de luz, mas, ao contrário, superabundância. A inacessibilidade divina funda e constitui todo possível acesso humano a Deus.

\section{Referências bibliográficas}

S. ANSELMI. Opera omnia. Ed. F.S.Schmitt. Stuttgart: Bad Cannstatt, 1984.

BOETHIUS. De topicis differentiis. Translated, with notes and an introduction by Eleonore Stump. London: Cornell University Press, 2004

- In Ciceronis topica. Translated, with notes and an introduction by Eleonore Stump. London: Cornell University Press, 1978.

CORBIN, M. La Pâque de Dieu. Quatre études sur S. Anselme de Cantorbéry. Paris: Cerf, 1997.

- Prière et dialectique. Introduction à l' oeuvre de S. Anselme de Cantorbéry, Paris: Cerf, 1992.

S. Anselme. Paris: Cerf, 2004.

52 Cf. RA. 8,137-8. 
LECLERCQ, J., L'amour des lettres et le désir de Dieu. 3. ed. Paris: Cerf, 1990.

SOUTHERN, R.W., Saint Anselm and his biographer. A study of monastic life and thought. Cambridge, 1966.

WARD, B., “Anselme of Canterbury. A monastic scholar”, In Fairacres publication 62 (1962).

\title{
RESUMO
}

Pode-se dizer que o Proslogion é uma meditação sobre o ser de Deus, realizada por um espírito que busca entender aquilo que inicialmente crê. Sua articulação conceitual é comandada pela presença do argumento único, que ao reconhecer que Deus é, aponta igualmente o modo pelo qual a criatura pode conceber algo de apropriado a respeito dele. O Proslogion nos oferecerá um caminho para pensar o sentido da busca de 'razões' no domínio exclusivo da fé, do esforço da palavra humana para encontrar aquilo que já fora dito por uma outra palavra. $\mathrm{O}$ objetivo deste estudo é considerar o sentido dessa racionalidade, do papel exercido pela razão no interior da inteligência da fé. Na primeira parte, aponto a tripla constituição do Proslogion, como exortação (excitatio), prova (probatio) e alegria (gaudium) final esperada pelo homem. Na segunda parte, indico o debate sobre a cogitatio humana, formulado na crítica de Gaunilo ao argumento e a conseqüente réplica de Anselmo.

\begin{abstract}
It can be said that the Proslogion is a meditation on the being of God, which is carried out by a spirit that seeks to understand what it initially believes. Its conceptual articulation is commanded by the presence of the unique argument, which, at the moment it recognizes the existence of God, it points the way by which the creature can conceive something appropriate about Him. The Proslogion will offer us a path to think over the sense of searching for "reasons" in the exclusive domains of faith, the effort of the human word to find that which was said before by someone else. The objective of this paper is to consider the sense of this rationality, the roles it performs inside the intelligence of faith. In the first part, I indicate the constitution of the Proslogion, as a warning (excitatio), a proof (probatio) and the final gladness (gaudium) hoped by man. In the second part, I indicate the debate regarding the human cogitatio, formulated in the Graunilo's review to the argument and the consequent Anselm's reply.
\end{abstract}

